\title{
Long-Term Stability of Metallic Iron inside Carbon Nanotubes
}

\author{
P. Kappen, ${ }^{*+}$ A. Rider, ${ }^{\neq}$P. J. Pigram, ${ }^{\dagger}$ and N. Brack ${ }^{\dagger}$ \\ ${ }^{+}$Centre for Materials and Surface Science and Department of Physics, La Trobe University, Victoria 3086, Australia \\ ${ }^{\ddagger}$ Defence Science and Technology Organisation, Fishermans Bend, Melbourne, Victoria 3207, Australia
}

Supporting Information

\begin{abstract}
Carbon nanotubes are important for the production of new materials with interesting electronic, magnetic, and mechanical properties. This study addresses the behavior of iron phases inside multiwalled carbon nanotubes grown from catalytic chemical vapor deposition (CCVD). Previous work had shown that the presence of metallic iron inside nanotubes is closely linked to CCVD production of long nanotubes at high yield. The long-term stability of the iron inside the nanotubes has not been investigated and is subject of this study. X-ray absorption spectroscopy (XAS) and X-ray photoelectron spectroscopy are employed to evaluate elemental and structural detail

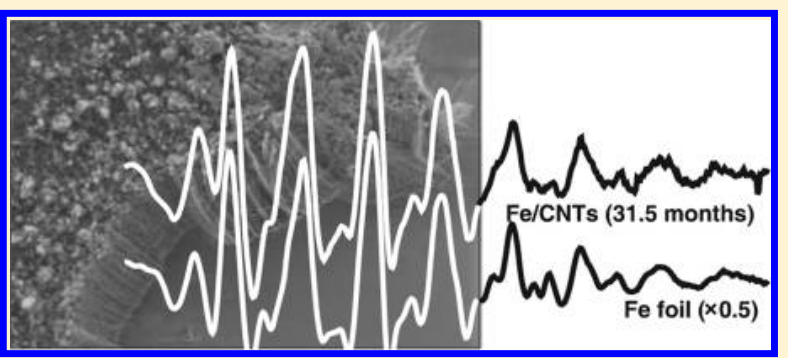
of nanotubes during storage over a period of close to three years. A basic heat treatment is also performed to assess the stability upon moderate thermal stress. The XAS results show that the metallic phases are stable over time and after heating. These outcomes demonstrate that the carbon nanotubes served as effective containers for the preservation of otherwise reactive phases; an important step toward producing products where the degradation of the contents inside carbon nanotubes is of critical importance.
\end{abstract}

\section{INTRODUCTION}

Carbon nanotubes (CNTs) continue to attract considerable attention due to their unique electrical and mechanical properties. They are used as field emission electrodes, as biosensors, in composite materials, in catalysts, and in consumer products. ${ }^{1-6}$ Carbon nanotubes can be produced by different methods including catalytic chemical vapor deposition (CCVD), for which a growth promoter is carried in the vapor phase to provide surface nucleation sites for the CNTs. A common growth promoter is ferrocene, $\mathrm{Fe}-\left(\mathrm{C}_{5} \mathrm{H}_{5}\right)_{2} \cdot{ }^{7-13}$ During the CCVD process, Fe from ferrocene is incorporated inside the CNTs.

Previous studies have shown Fe phases in CNTs to be present as iron carbides or as metallic Fe (e.g., refs 11 and 14-16). In one of the previous studies from this group, ${ }^{14}$ data were presented from CNTs grown in a large $(V=16 \mathrm{~L}) \mathrm{CCVD}$ reactor, showing that under most reaction conditions CNTs containing iron carbides were produced. However, under certain growth parameters, disordered metallic $\mathrm{Fe}(\alpha$-Fe) was formed inside the nanotubes. In that particular case, the nanotubes containing $\alpha$-Fe were up to 8 times longer $(320 \mu \mathrm{m})$ than the CNTs containing carbides, and the production yield (59\%) was about twice as high as for the nanotubes containing iron carbides (see Table 3 in ref 14). The incorporation of metallic iron in these nanotubes opens interesting application perspectives whereby the iron may act as nanowires or the CNTs may be an effective way of shielding Fe nanoparticles from air exposure and, thus, oxdiation. The oxidation behavior of iron bulk surfaces and of nanomaterials is well understood. Upon exposure to oxygen and at room temperature and moderately elevated temperatures (e.g., $100{ }^{\circ} \mathrm{C}$ ), iron forms within minutes an oxide layer of a few nanometers thickness (e.g., refs 17-21), and even at low oxygen partial pressure of only $10-7 \mathrm{mbar}$, a $2 \mathrm{~nm}$ thick surface oxide layer forms within $20 \mathrm{~min}$ of exposure (ref 22 and references therein). Everyday experience furthermore shows that under ambient conditions with moderate humidity $(\mathrm{RH}>50 \%)$, bulk iron corrodes within a matter of weeks to months.

Potential novel applications based on systems such as carbon nanotubes containing iron and their magnetic and electric properties include spintronics, high-density storage devices, and tumor therapy. ${ }^{7,23,24}$ From the point of view of production output and product quality, then, the CCVD synthesis route leading to metallic Fe inside the CNTs has a number of advantages. While effort needs to be made to assess specific microscopic CNT properties and optimize production parameters, consideration of the stability of one of the nanotubes' key functional parameters, that is, the metal content inside the tubes, is also required. If one of the goals of CNT research is to develop carbon nanotubes for a wide field of applications based on the contents inside the nanotubes, then the long-term stability of $\mathrm{CNTs}$ is central to ensure proper functionality and sufficient shelf life of the corresponding product or material. Some aspects of the stability of CNTs have been previously investigated: Field emission electrodes have shown no or little degradation under working conditions for up to about $100 \mathrm{~h},{ }^{25-28}$ and biosensors and electrodes exhibited good stability over weeks to months. ${ }^{29-31}$ However, little attention has so far been drawn to the structural

Received: August 17, 2011

Revised: September 22, 2011

Published: September 26, 2011 
stability of metallic phases inside CNTs. It can be expected, however, that degradation of the metallic cores will impact the properties of the nanotubes. In the case of the study presented here, the preservation of the specific structure and valence state of the iron inside the CNTs is vital for further development of ironcontaining carbon nanotubes and for successfully linking CNT qualities (e.g., length) and production parameters (e.g., yield) to their microstructure and their stability. Investigating the shelf life of CCVD synthesized carbon nanotubes is thus one of the next steps toward developing future applications and markets.

This study focuses on the structural stability of Fe inside CCVD-grown multiwalled CNTs (MWCNTs) over a long-term period of close to 3 years. In order to assess the Fe structure inside the nanotubes, X-ray absorption spectroscopy (XAS) was chosen as it allows heavier metals (e.g., Fe) encapsulated in a light matrix (e.g., C) to be investigated element-specifically, nondestructively, and without complex sample preparation procedures. $\mathrm{X}$-ray absorption spectroscopy was used to monitor structural and chemical changes in the Fe phases. The material for this work was chosen from a previous XAS study whereby the iron was found to be present in the metallic state. ${ }^{14}$ Analyses were performed at $t=0,3.5,17.5$, and 31.5 months of storage, respectively. The extended X-ray absorption fine structure (EXAFS) results are supported by depth profiling X-ray photoelectron spectroscopy (XPS) analyses. At $t=31.5$ months, a basic heat treatment of the CNTs was carried out to investigate structural stability under moderate thermal stress. All results show a high degree of structural stability of the iron.

\section{EXPERIMENTAL SECTION}

Carbon nanotubes from a previous study, ${ }^{14}$ were used at specific times during storage $(t=0,3.5,17.5$, and 31.5 months $)$. The MWCNTs were stored in a closed but unsealed vial in a laboratory environment around $21^{\circ} \mathrm{C}$ and $55 \%$ relative humidity $(\mathrm{RH})$. At $t=31.5$ months, a subsample was taken, placed in a Petri dish, and stored for $15 \mathrm{~h}$ at $80^{\circ} \mathrm{C}$ to assess the thermal stability of the encapsulated phases upon short-term exposure to elevated temperatures after long-term storage.

For XAS experiments, ca. 40-50 mg of MWCNT powder was sampled from the vial, carefully mixed with $50-100 \mathrm{mg}$ of cellulose powder (Sigma-Aldrich, $20 \mu \mathrm{m}$ particle size), and pressed to $13 \mathrm{~mm}$ diameter disks by use of a manual hydraulic pellet press (Specac). XAS data were acquired at the Australian Synchrotron and at the Hamburg Synchrotron Radiation Laboratory (HASYLAB), Germany. Scans were recorded at the $\mathrm{Fe}-\mathrm{K}$ absorption edge in transmission mode at room temperature. The photon energy was controlled by use of Si (111) doublecrystal monochromators at both synchrotron facilities (see also ref 14). Data were processed and modeled by use of the freeware VIPER $^{32}$ Spectra were background-subtracted, the EXAFS oscillations above the absorption edge were extracted $\left[\chi(k) k^{2}\right]$, and Fourier transformations were obtained. Models and fits were performed in $k$-space using the first two major coordination shells ( $R \in[1.1 \AA ; 4.0 \AA])$ after Fourier back-transformation. The fit model was based on previous results ${ }^{14}$ using single-scattering $(\mathrm{Fe}-\mathrm{Fe})$ and multiple-scattering paths $(\mathrm{Fe}-\mathrm{Fe}-\mathrm{Fe})$ derived from the structure of $\alpha$-Fe; the models also included an $\mathrm{Fe}-\mathrm{O}$ contribution to assess the presence of oxidized iron. All paths were calculated with FEFF $6 \mathrm{~L}^{33}$

XPS analyses were performed on fresh and stored (31.5 months; room temperature) MWCNTs, on laboratory X-ray

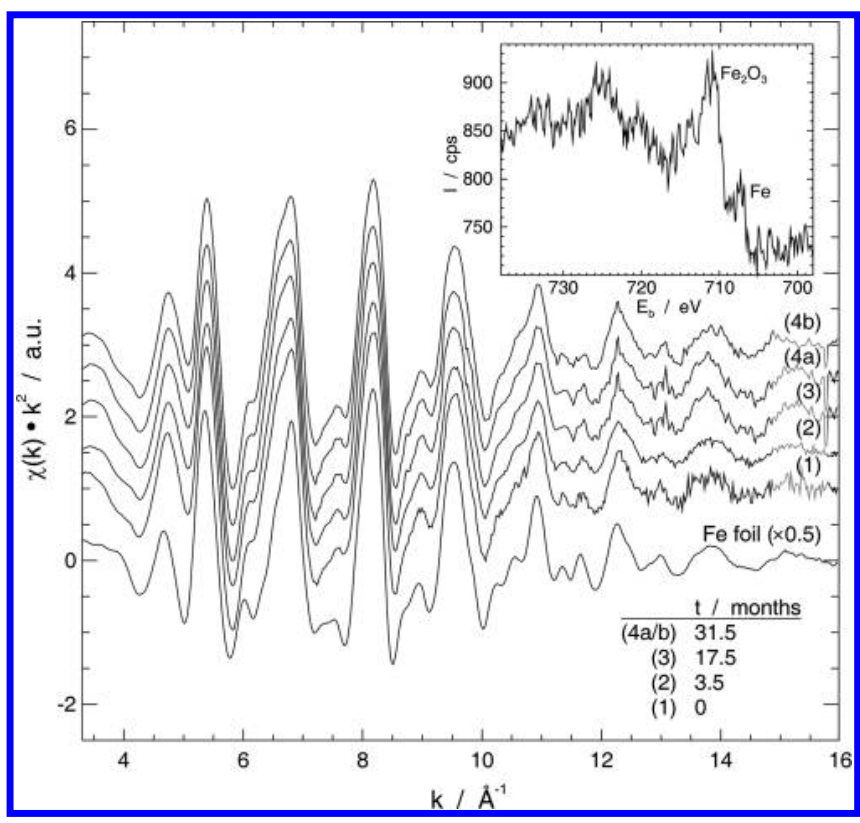

Figure 1. Weighted EXAFS spectra $\chi(k) k^{2}$ of MWCNTs after increasing periods of storage in ambient conditions (traces 1-4a) and of MWCNTs after long-term storage and additional heating (trace 4b). Also included is the spectrum of metallic $\mathrm{Fe}$, scaled by a factor of 0.5 for presentation purposes. (Inset) XPS data of fresh MWCNTs (1).

instruments with monochromatic $\mathrm{Al} \mathrm{K} \alpha$ sources (Kratos Axis Ultra and Kratos Nova, respectively; $I=10 \mathrm{~mA}$; $U=15 \mathrm{kV}$; analysis area $700 \times 300 \mu \mathrm{m}^{2}$ ). Charge neutralizers were employed to ensure spectral quality. The fresh MWCNTs were analyzed in powder form as received. The stored MWCNTs were in the form of vertically aligned forests of carbon nanotubes that had been grown directly onto quartz glass slides. The slides were then infused with room-temperature curing epoxy resin and a torque stub was bonded to the surface of the MWCNT-resin coating. Once the resin was cured, force was applied to the torque stub until the resin and MWNT coating was sheared off the quartz slide. Failure of the resin and MWCNT coating typically occurred in close proximity to the coating and quartz interface. XPS analysis of the failed coating surface in conjunction with argon ion beam etching provided the ability to interrogate the chemical condition of the iron catalyst contained within the MWNTs. Scanning electon microscopy (SEM; field emission LEO 1530VP) was used to confirm that MWCNTs were entirely removed from the quartz surface and that the MWCNTs had grown predominantly perpendicularly to the quartz substrate, thus enabling XPS depth profiling along the nanotube axes. For depth profiling in the XPS instrument, the resin-embedded nanotubes were etched with an Ar ion gun (ion gun beam energy $E=4 \mathrm{keV}$; extractor current $I=140 \mathrm{~mA}$; source $U=3.8 \mathrm{kV}$; etch area $3 \times 3 \mathrm{~mm}^{2}$ ).

\section{RESULTS AND DISCUSSION}

Figure 1 shows EXAFS oscillations $\chi(k) k^{2}$ for the nanotube samples as a function of storage time. Also included are the spectra of the stored plus heated MWCNTs and of metallic iron $(\alpha-\mathrm{Fe})$. The first spectrum in the series $(t=0)$ and the spectrum of $\alpha$-Fe were reported previously ${ }^{14}$ and are included to illustrate the long-term storage behavior of the nanotubes. The EXAFS data presented exhibit only minor differences with fine structures, 
Table 1. Average of EXAFS Fit Results of MWCNTs Stored at Room Temperature ${ }^{a}$

\begin{tabular}{|c|c|c|c|c|c|c|c|c|c|}
\hline scattering path $i$ & $R_{i}, \AA$ & $\delta^{\prime}\left(R_{i}\right), \AA$ & $\sigma\left(R_{i}\right), \AA$ & $N_{i}$ & $\delta^{\prime}\left(N_{i}\right)$ & $\sigma\left(N_{i}\right)$ & $s_{i}, 10^{-3} \AA^{-2}$ & $\delta^{\prime}\left(s_{i}\right), 10^{-3} \AA^{-2}$ & $\sigma\left(s_{i}\right), 10^{-3} \AA^{-2}$ \\
\hline $\mathrm{Fe}-\mathrm{Fe}(8 ; 2.486 \AA)$ & 2.48 & 0.00 & $<0.01$ & 6.4 & 0.2 & 0.8 & 7.4 & 0.2 & 0.5 \\
\hline $\mathrm{Fe}-\mathrm{Fe}(6 ; 2.870 \AA)$ & 2.82 & 0.01 & 0.01 & 4.7 & 0.4 & 0.6 & 12.5 & 0.6 & 1.9 \\
\hline $\mathrm{Fe}-\mathrm{Fe}(12 ; 4.059 \AA)$ & 4.02 & 0.01 & 0.01 & 8.1 & 1.0 & 1.2 & 12.5 & 0.1 & 1.9 \\
\hline $\mathrm{Fe}-\mathrm{Fe}-\mathrm{Fe}(48+24 ; 3.921 \AA)$ & 3.84 & 0.03 & 0.02 & 46.5 & 6.7 & 1.8 & 13.6 & 3.9 & 3.3 \\
\hline $\mathrm{Fe}-\mathrm{Fe}-\mathrm{Fe}(48+24 ; 4.515 \AA)$ & 4.53 & 0.07 & $<0.01$ & 43.9 & 29.7 & 1.9 & 22.8 & 1.4 & 7.1 \\
\hline $\mathrm{Fe}-\mathrm{O}(3 ; 1.946 \AA)$ & 1.91 & 0.03 & 0.01 & 0.7 & 0.2 & 0.2 & 7.5 & 0.5 & 0.5 \\
\hline
\end{tabular}

${ }^{a}$ Due to the similarity of the individual fits, the averages of the corresponding parameters are reported here. These fit parameters are the coordination sphere radii $R_{i}$, coordination numbers $N_{i}$, disorder factors $s_{i}$, and energy shift $E_{0}$. The energy shift was set as a global fit parameter: $E_{0}=6.6 \mathrm{eV}, \delta^{\prime}\left(E_{0}\right)=$ $0.3 \mathrm{eV}$, and $\sigma\left(E_{0}\right)=0.5 \mathrm{eV}$. The disorder factors for $\mathrm{Fe}-\mathrm{Fe}(-\mathrm{Fe})$ scattering paths were constrained to be greater for shells with greater path lengths.

oscillation frequencies, and amplitudes very similar for all MWCNT spectra. This result qualitatively indicates that the iron phases associated with the nanotubes did not change significantly over time.

XPS data of fresh nanotubes $(t=0)$ showed Fe present only at minor levels $(<1$ at. \%) with most of the iron detected in the fully oxidized state, $\mathrm{Fe}_{2} \mathrm{O}_{3}$, as expected. ${ }^{34}$ Given that the depth of XPS analysis is on the order of $2-5 \mathrm{~nm}$, the iron detected may be attributed to residual decomposed ferrocene on the surface of the nanotubes. This result is also supported by SEM analyses; previous energy-dispersive spectroscopy measurements have shown that most of the elemental iron is present inside the nanotubes. ${ }^{34}$ The EXAFS data presented in Figure 1 were analyzed further in order to assess the atomic near-range structure of $\mathrm{Fe}$ inside the nanotubes. Corresponding fit results are summarized in Table 1 with the fits performed in $k$-space after Fourier forward and backtransforms (see Figure 2). Very good agreement between data and fit could be achieved over almost the entire $k$-range. Only at high $k$-values (ca. > $14 \AA^{-1}$ ) could some more prominent deviations be observed. However, these deviations were close to the noise level of the data before Fourier transformation and were, thus, not significant. For each spectrum, the fit results were generally similar, reflecting the similarities between the $\chi(k)$ shown in Figure 1. Hence, the results for the four individual EXAFS spectra before heating were averaged as presented in Table 1. For each parameter, $R_{i}, N_{i}$, and $s_{i}$, two uncertainty values are reported: $\sigma$, the standard deviation, indicating the variation between data points contributing to the averages; and $\delta^{\prime}$, the average of the four individual uncertainties per parameter before averaging, indicating the uncertainty for each data point. As anticipated from comparison of the spectra of MWCNTs with that of metallic Fe (Figure 1), the radial distances, $R_{i}$, of the fitted scattering paths agreed well with the expected values for metallic iron. The uncertainties of $R_{i}$ were small, indicating little variation of this parameter across the different fits as shown by the similar frequencies of oscillations and structures in Figure 1. The reduced amplitude of the EXAFS oscillations was reflected in reduced coordination numbers, $N_{i}$, and increased disorder factors ("DebyeWaller" factors), $s_{i}$. These parameters are linked. Decreasing $N_{i}$ can, to some degree, be compensated by increasing $s_{i}$. However, it should be noted that, in the EXAFS equation, $N_{i}$ occurs as a linear factor, whereas $s_{i}$ is included as $\exp \left(-2 k^{2} s_{i}^{2}\right)$. Hence, $N_{i}$ applies as a linear scaling factor to the whole $\chi(k)$ independent of $k$, while $s_{i}$ applies as an attenuation factor primarily to higher $k$. In Figure 1, the relative oscillation amplitudes within the envelope of the MWCNT data were similar to those of metallic Fe (note that the spectrum of $\mathrm{Fe}$ was scaled by 0.5 for presentation purposes). Hence the reduced amplitudes in the MWCNTs were primarily

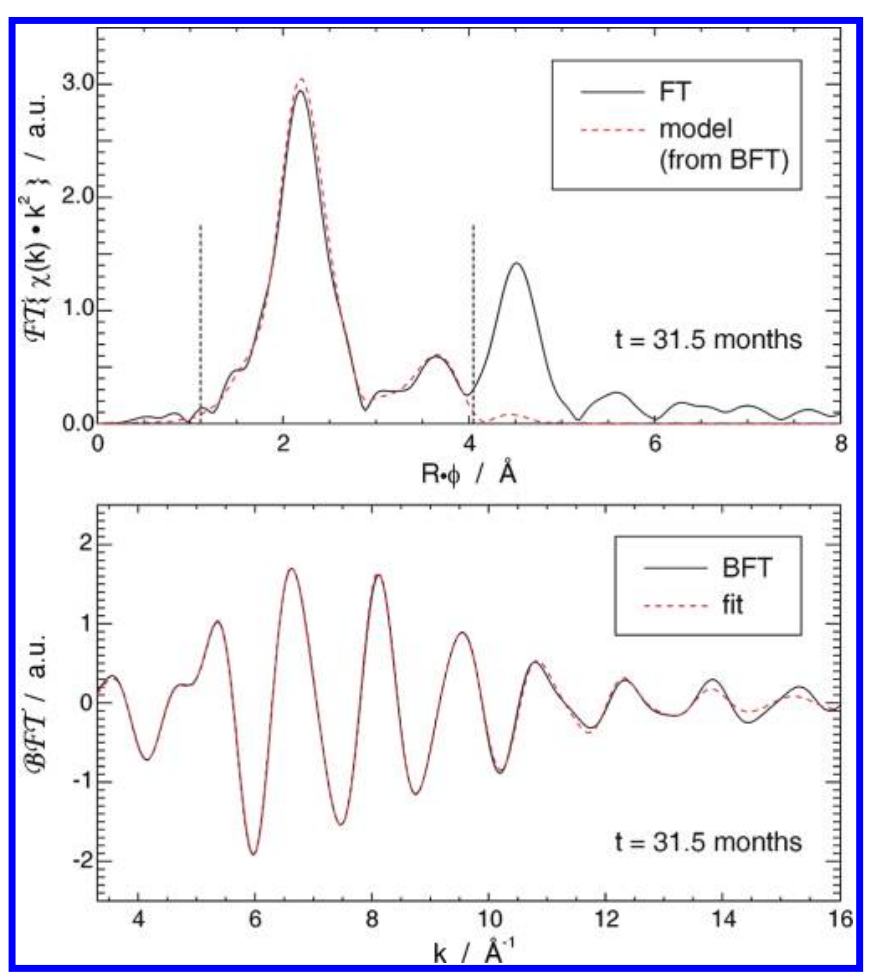

Figure 2. Example of Fourier-transformed (FT) and back-transformed (BFT) data of MWCNTs (here at $t=31.5$ months), including fit results after modeling by use of scattering paths as described in Table 1 . The vertical dashed lines in the top panel indicate neighbor shells that were included in the BFT.

associated with a reduction in the coordination numbers. The fit results in Table 1 support this expectation, whereby the coordination numbers were distinctly reduced compared to the values for $\alpha-F e$. The reduction in $N_{i}$ is typical for nanoparticles, where the fraction of atoms at the surface is increased compared to the number of bulk atoms, and hence, an increased number of atoms are not fully surrounded by neighboring atoms. Furthermore, the reduced amplitude was affected by an increase in disorder in the structure as reflected in the increased parameters $s_{i}$. These fit results were consistent with the results obtained earlier by the authors (see Table S1 in Supporting Information, taken from ref 14), where it was concluded that amplitude reduction by a factor of ca. 0.5 compared to metallic Fe (see also Figure 1) could not exclusively be explained by missed scattering paths (i.e., neighbors $N_{i}$ ) but that increased structural disorder also needed to be taken into account. For 
modeling of the EXAFS data in this study, also a small contribution owing to the presence of $\mathrm{Fe}_{2} \mathrm{O}_{3}$ was taken into account. This

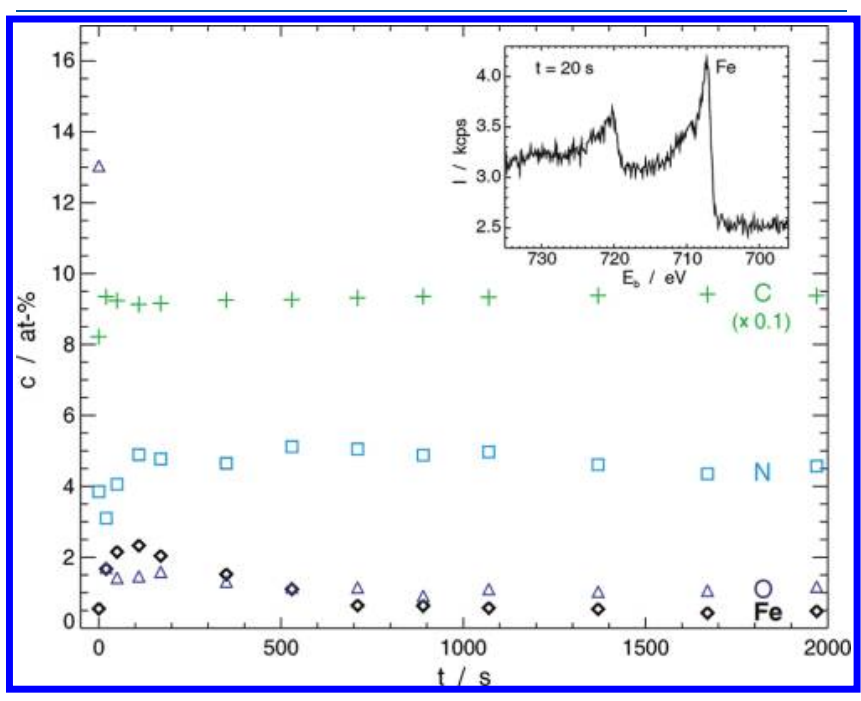

Figure 3. Elemental concentrations of $\mathrm{Fe}, \mathrm{O}, \mathrm{N}$, and $\mathrm{C}$, derived from XPS spectra as a function of etching time during depth profiling through MWCNTs embedded in an epoxy resin. For presentation purposes, the carbon concentration (green crosses) is displayed at 10 times less than actual values. (Inset) XPS data after etching for $t_{\mathrm{e}}=20 \mathrm{~s}$.

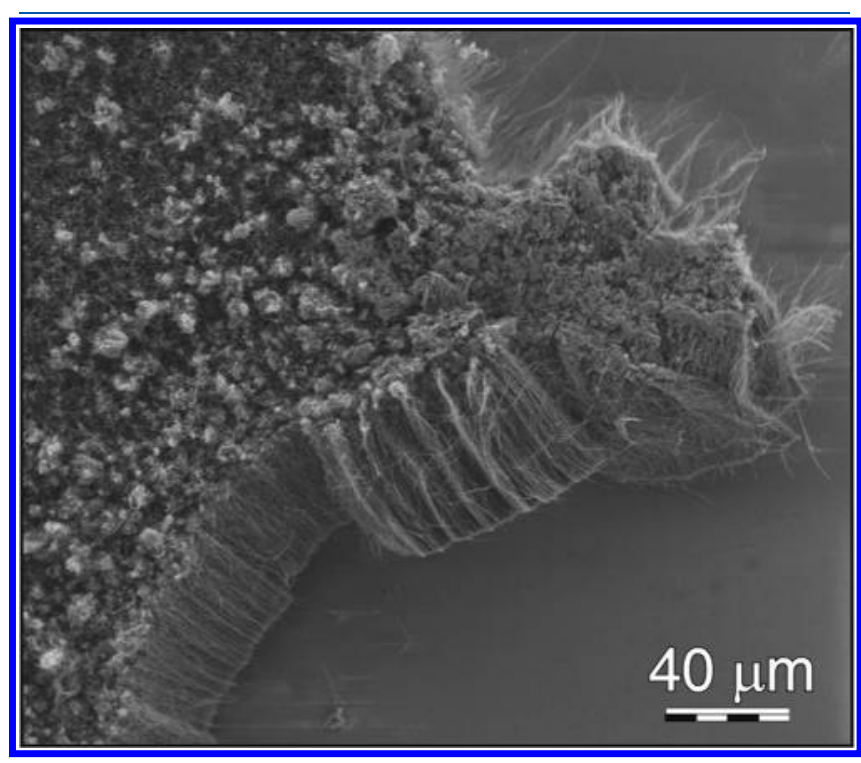

Figure 4. SEM micrograph of MWCNTs grown in a dense carpetlike arrangement. contribution was indicated by a weak shoulder at the leading edge of the first peak of the Fourier transform (see Figure 2a). Including a corresponding $\mathrm{Fe}-\mathrm{O}$ single scattering path in the model facilitated a good fit as shown in Figure $2 \mathrm{~b}$, whereby the reduced intensity of the $\mathrm{Fe}-\mathrm{O}$ signal $\left(\mathrm{N}_{\mathrm{Fe}-\mathrm{O}}=0.7 \pm 0.2\right)$ contributed only to the $\chi(k)$ at low $k$ and, thus, did not significantly alter the general fit results of the metallic Fe. This was reflected in the fact that the parameters obtained in Table 1 were consistent with previous work where no $\mathrm{Fe}-\mathrm{O}$ contribution was considered. In the study presented here, however, the potential contribution of iron oxide was an important aspect of assessing potential degradation of the iron phases inside the nanotubes upon exposure to air. Overall, it was found that the coordination number for $\mathrm{Fe}-\mathrm{O}$ scattering paths did not change as a function of storage and that the presence of these paths was explained by the presence of small amounts of $\mathrm{Fe}_{2} \mathrm{O}_{3}$ on the outside of the nanotubes, as found previously by XPS. Given that the inner diameter of the nanotubes was previously found to be ca. $25 \mathrm{~nm}$, a thin oxide layer of only $2 \mathrm{~nm}$ (see Introduction) would have comprised approximately $40 \%$ of the volume of the iron phases and would have readily been detected by EXAFS. The EXAFS fit results presented so far and their consistency with previous findings, thus, quantitatively support the stability of the disordered Fe phases inside the nanotubes over time. Since the system considered here effectively consists of only two components, $\mathrm{C}$ from carbon nanotubes and $\mathrm{Fe}$ from iron inside the nanotubes, and since exposure to oxygen (air) would have led to a significant contribution of iron oxide signals in the EXAFS data, it can be concluded that the presence of carbon in the form of MWCNTs was the factor stabilizing the otherwise reactive iron phases.

In Figure 3, XPS depth-profiling results are shown for the fracture surface of MWCNT and resin coating prepared from MWCNTs at $t=31.5$ months. These nanotubes had grown in a carpetlike structure primarily perpendicular to the substrate. A corresponding SEM image of a typical nanotube flake is presented in Figure 4. The structures shown in the image are representative of the MWCNTs used for the XPS experiments in this study. As described above, the nanotubes had been embedded in an epoxy resin, and the resin had been sheared off the substrate. Depth profiling was performed on the failed coating side and the corresponding elemental concentrations of $\mathrm{Fe}, \mathrm{C}, \mathrm{O}$, and $\mathrm{N}$ are shown in Figure 4 as a function of etching time, $t_{\mathrm{e}}$. The first data point before etching $\left(t_{\mathrm{e}}=0 \mathrm{~s}\right)$ reflects the initial state of the fracture surface and indicates the iron concentration is very low $(\sim 0.5$ at. \%). At $t_{\mathrm{e}} \approx 120 \mathrm{~s}$, the $\mathrm{Fe}$ concentration shows a broad maximum at just under 2.5 at. \%. After $200 \mathrm{~s}$ of etching, the iron concentration decreases and plateaus to a value of 0.5 at. \%. The presence of iron is attributed to iron species within the nanotubes, given the

\section{Table 2. EXAFS Fit Results of $\mathrm{MWCNTs}^{a}$}

$\begin{array}{lrrrrrc}t=31.5 \text { months }+15 \mathrm{~h} \text { at } 80^{\circ} \mathrm{C} & R_{i} \AA & \delta^{\prime}\left(R_{i}\right), \AA & N_{i} & \delta^{\prime}\left(\mathrm{N}_{i}\right) & s_{i}, 10^{-3} \AA^{-2} & \delta^{\prime}\left(s_{i}\right), 10^{-3} \AA^{-2} \\ \mathrm{Fe}-\mathrm{Fe}(8 ; 2.486 \AA) & 2.48 & <0.01 & 5.8 & 0.2 & 7.2 & 0.3 \\ \mathrm{Fe}-\mathrm{Fe}(6 ; 2.870 \AA) & 2.82 & 0.01 & 4.5 & 0.4 & 13.0 & 1.1 \\ \mathrm{Fe}-\mathrm{Fe}(12 ; 4.059 \AA) & 4.02 & 0.01 & 7.6 & 1.1 & 13.1 & 0.4 \\ \mathrm{Fe}-\mathrm{Fe}-\mathrm{Fe}(48+24 ; 3.921 \AA) & 3.86 & 0.03 & 45.6 & 11.1 & 14.4 & 6.2 \\ \mathrm{Fe}-\mathrm{Fe}-\mathrm{Fe}(48+24 ; 4.515 \AA) & 4.54 & 0.08 & 44.5 & 34.0 & 25.1 & 16.7 \\ \mathrm{Fe}-\mathrm{O}(3 ; 1.946 \AA) & 1.91 & 0.03 & 0.5 & 0.2 & 7.3 & 0.2\end{array}$

${ }^{a}$ After $t=31.5$ months of storage at room temperature plus additional heat treatment at $80{ }^{\circ} \mathrm{C}$ for $15 \mathrm{~h}$.For details on the individual fit parameters and their constraints, see Table 1 . 
geometry of the sample and the direction of the depth profiling, which would expose the cross-sectional area of the vertically aligned nanotube array. During the depth profile, high-resolution region scans of the $\mathrm{Fe} 2 \mathrm{p}_{3 / 2}$ emission line confirmed the iron to be present in the metallic state (see Figure 3 inset), thus supporting the validity of the EXAFS analyses.

In addition to storage at room temperature, a sample of the MWCNTs was also subjected to a moderate heat treatment for $15 \mathrm{~h}$ at $80^{\circ} \mathrm{C}$ at the end of the storage period. This treatment was used to investigate the stability of the iron phases under some elevated thermal stress after long-term storage, thus simulating conditions that may occur in materials or products for short periods of time at some point during their life cycle. The corresponding EXAFS fit results are summarized in Table 2 . Since only one sample was investigated, no standard deviation $\sigma$ is given. The data show that, also after heating, the iron phases remained in their disordered metallic state. Interatomic distances, coordination numbers, and disorder factors were consistent with the data of the MWCNTs stored at room temperature, and no increase in the coordination number corresponding to $\mathrm{Fe}-\mathrm{O}$ scattering paths was observed.

\section{CONCLUSION}

In this study, the iron phases inside multiwalled carbon nanotubes were investigated as a function of storage under ambient conditions over a period of more than 2.5 years. It was found that the iron remained stable in a metallic state with the atomic near-range structure consistently showing an elevated level of disorder when compared to that of $\alpha-\mathrm{Fe}$ (bcc-Fe). Subjecting the nanotubes to elevated temperatures $\left(80{ }^{\circ} \mathrm{C}\right)$ over a short period of time $(15 \mathrm{~h})$ did not alter the structure of the iron, thus indicating stability under conditions that may typically be encountered either during manufacturing or during operation of the final product or material. These findings show that the nanotubes acted as an inert container for the storage and preservation of otherwise quickly oxidizing metallic phases under common storage or moderate thermal stress conditions. Preservation of the metallic state is important when it comes to securing the shelf life of products and materials that are dependent on stability and integrity of the metallic phases contained within carbon nanotubes.

\section{ASSOCIATED CONTENT}

S Supporting Information. One table, showing EXAFS fit results for $\alpha-\mathrm{Fe}$ and sample $\mathrm{C}$ as reported previously. ${ }^{14}$ This material is available free of charge via the Internet at http:// pubs.acs.org.

\section{AUTHOR INFORMATION}

\section{Corresponding Author}

*E-mail p.kappen@latrobe.edu.au; phone +61-3-9479 1329; fax +61-3-9479-1552.

\section{ACKNOWLEDGMENT}

We thank Dr. Chris Glover and Dr. Bernt Johannessen (Australian Synchrotron) and Dr. Edmund Welter (HASYLAB) for assistance and support during the XAS beamtimes and Eudora Yeo for assistance in preparation of CNT samples. Dr. Barrry Halstead is gratefully acknowledged for providing the samples for this study.

\section{REFERENCES}

(1) Chang, K. It Slices! It Dices! Nanotube Struts Its Stuff. In The New York Times, July 16, 2002.

(2) Dresselhaus, M. S.; Dresselhaus, G.; Eklund, P. C. Science of Fullerenes and Carbon Nanotubes; Academic Press: San Diego, CA, 1996.

(3) Durkop, T.; Getty, S. A.; Cobas, E.; Fuhrer, M. S. Nano Lett. 2004, 4, 35

(4) Potential Applications of Carbon Nanotubes; Endo, M.; Strano, M. S.; Ajayan, P. M., Eds.; Springer-Verlag: Berlin and Heidelberg, Germany, 2008; Vol. 111, p 13.

(5) Gooding, J. I. Electrochim. Acta 2005, 50, 3049.

(6) Yuzvinsky, T. D.; Fennimore, A. M.; Mickelson, W.; Esquivias, C.; Zettl, A. Appl. Phvs. Lett. 2005, 86, No. 053109.

(7) Costa, S.; Borowiak-Palen, E.; Bachmatiuk, A.; Rummeli, M. H.; Gemming, T.; Kalenezuk, R. I. Phvs. Status Solidi B 2007, 244, 4315.

(8) Heresanu, V.; Castro, C.; Cambedouzou, J.; Pinault, M.; Stephan, O.; Reynaud, C.; Mayne-L'Hermite, M.; Launois, P. I.Phys. Chem. C 2008, $112,7371$.

(9) Jin-Phillipp, N. Y.; Ruhle, M. Phys. Rev. B 2004, 7024, 5421.

(10) Kim, H.; Kaufman, M. J.; Sigmund, W. M.; Jacques, D.; Andrews, R. I. Mater. Res. 2003, 18, 1104.

(11) Kim, H.; Sigmund, W. Carbon 2005, 43, 1743.

(12) Kim, H.; Sigmund, W. I. Crvst. Growth 2005, 276, 594.

(13) Liu, Z. J.; Che, R. C.; Xu, Z. D.; Peng, L. M. Sunth. Met. 2002, $128,191$.

(14) Kappen, P.; Halstead, B.; Rider, A.; Pigram, P. J.; Brack, N. I. Phvs. Chem. C 2009, 113, 4307.

(15) Kopelev, N. S.; Chechersky, V.; Nath, A.; Wang, Z. L.; Kuzmann, E.; Zhang, B. S.; Via, G. H. Chem. Mater. 1995, 7, 1419.

(16) Wu, W. Z.; Zhu, Z. P.; Liu, Z. Y.; Xie, Y. I.; Zhang, J.; Hu, T. D. Carbon 2003, 41, 317.

(17) Giri, S.; Ganguli, S.; Bhattacharya, M. Appl. Surf. Sci. 2001, 182, 345.

(18) Haneda, K.; Morrish, A. H. Nature 1979, 282, 186.

(19) Kashiwakura, T.; Nakai, S. Radiat. Phys. Chem. 2006, 75, 1888.

(20) Linderoth, S.; Morup, S.; Bentzon, M. D. I. Mater. Sci. 1995, 30, 3142 .

(21) Tamura, I.; Hayashi, M. Surf. Sci. 1984, 146, 501.

(22) Lawless, K. R. Rep. Prog. Phys. 1974, 37, 231.

(23) Lipert, K; Bahr, S.; Wolny, F.; Atkinson, P.; Weissker, U.; Muhl, T.; Schmidt, O. G.; Buchner, B.; Klingeler, R. Appl. Phvs. Lett. 2010, 97, 12503.

(24) Elias, A. L.; Rodriguez-Manzo, J. A.; McCartney, M. R.; Golberg, D.; Zamudio, A.; Baltazar, S. E.; Lopez-Urias, F.; Munoz-Sandoval, E.; Gu, L.; Tang, C. C.; Smith, D. J.; Bando, Y.; Terrones, H.; Terrones, $\underline{M}$. Nano Lett. 2005, 5, 467.

(25) Araki, H.; Katayama, T.; Yoshino, K. Appl. Phvs. Lett. 2001, 79, 2636.

(26) Chen, L. C.; Hong, W. K.; Tarntair, F. G.; Chen, K. J.; Lin, J. B.; Kichambare, P. D.; Cheng, H. C.; Chen, K. H. New Diamond Front. Carbon Technol. 2001, 11, 249.

(27) Jung, H. Y.; Jung, S. M.; Kim, L.; Suh, J. S. Carbon 2008, 46, 969.

(28) Torabi, M.; Sadrnezhaad, S. K. Curr. Appl. Phvs 2010, 10, 72.

(29) Akhgar, M. R.; Salari, M.; Zamani, H.; Changizi, A.; HosseiniMahdiabad, H. Int. J. Electrochem. Sci 2010, 5, 782.

(30) Li, J. J.; Yuan, R.; Chai, Y. Q.; Che, X. L.Mol. Catal. B: Enzym. 2010, 66, 8.

(31) Ye, J. S.; Wen, Y.; Zhang, W. D.; Cui, H. F.; Xu, G. Q.; Sheu, F. S. Electroanalusis 2005, 17, 89.

(32) (a) Klementiev, K. V. VIPER for Windows (freeware): http:// www.cells.es/Beamlines/CLAESS/software/viper.html (accessed April 2011). (b) Klementiev, K. V. I. Phvs. D: Appl. Phvs. 2001, 34, 209-217.

(33) Ravel, B.; Newville, M. I. Synchrotron Radiat. 2005, 12, 537.

(34) Halstead, B. W.; Brack, N.; Rider, A. N.; Yeo, E.; Pigram, P. J.; Glaisher, R.; McCulloch, D. G. Scaled-up production of multi-walled carbon nanotubes using catalytic chemical vapour deposition. 2006 International Conference on Nanoscience and Nanotechnology (ICONN), Brisbane, Australia, 2006. 